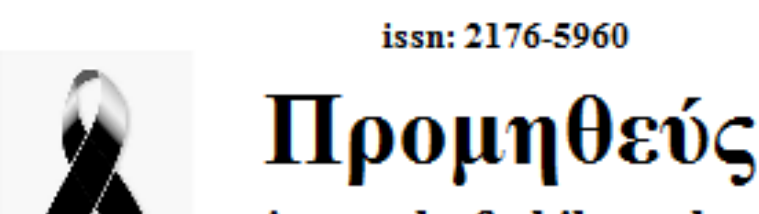 journal of philosophy \\ n. 35 Ienuery/April 2021
}

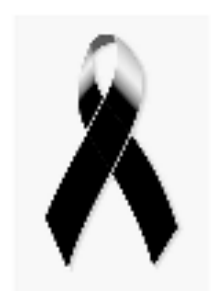

\section{JULIAN ASSANGE: O ARAUTO PÓS-MODERNO DA PARRHESIA GRECO-ROMANA}

\section{Vanessa Cordeiro Kiewel Mestranda em filosofia pela UnB}

\begin{abstract}
"Se você quer saber a verdade, então ninguém vai lhe contar a verdade, vão contar apenas a versão deles. Então, você quer a verdade? Vai ter que buscar você mesmo. Aí é onde mora o verdadeiro poder da sua vontade de ver além dessa história e de qualquer outra história. E, enquanto você continua buscando, você representa um perigo para eles. É disso que eles têm medo, de você. Tudo tem a ver com você... e um pouquinho comigo também".

Julian Assange
\end{abstract}

(Comentário final ao filme "O quinto poder"1)

"Publique e seja amaldiçoado".

Scotty Reston apud LEIGH, $2011^{2}$.

\footnotetext{
${ }^{1}$ O QUINTO PODER (THE FIFTH ESTATE). Diretor Bill Condon. Estados Unidos: Dreamworks, 2013. Disponível em: https://youtu.be/iZtrX03P 0s . Acesso em 26 set. 2020.

${ }^{2}$ LEIGH, David; HARDING, Luke. WikiLeaks: a guerra de Julian Assange contra os Segredos de Estado. Campinas (SP): Verus, 2011, Edição Kindle, posição 380.
} 
RESUMO: A parrhesia grega e seu equivalente romano, a libertas, era o dever cívico de dizer a verdade, toda a verdade, perante os poderosos (governantes) para defender um princípio ou direito importante para toda a sociedade, independentemente dos riscos pessoais reais que aqueles que a exerciam poderiam sofrer, inclusive a própria morte.. No período da antiguidade clássica, era defendida e praticada por Sócrates e pelas escolas filosóficas derivadas de seu pensamento, em especial o cinismo e o estoicismo. Aqui focamos na parrhesia como uma forma de exercer a ação comunitária ou sócio-política estoica, priorizando o bem maior do todo, e a trazemos para a contemporaneidade, encontrando na figura de Julian Assange o maior representante vivo da parrhesia que, pela natureza mesma do conceito, ao realizar o bem comum para todas e todos ao denunciar e mostrar a verdade sobre as ações corruptas, crimes de guerra e crimes contra a humanidade de vários governos e empresas, se tornou o alvo de poderosa perseguição, campanha de difamação e tentativa, infelizmente bem sucedida, de tornálo um pária internacional. Agora, quando de seu julgamento acerca da sua possível extradição para os Estados Unidos, vem sofrendo ainda mais, num julgamento kafkiano e sendo submetido à tortura psicológica e física. Todavia, por mais que sofra injustiças incontáveis há longos dez anos e que possa ser extraditado para os Estados Unidos e lá sofrer novo julgamento injusto, tratamento desumano e cruel, bem como ser condenado a uma pena de reclusão de tal extensão que se tornará pena capital, uma prisão perpétua, tudo o que ele nos deu corajosamente na defesa da liberdade de expressão, da liberdade de imprensa e do direito de saber o que os governantes fazem em nossos nomes sem a nossa autorização, jamais será esquecido e continuará a ser multiplicado eternamente, como uma caixa de Pandora que expele todos os males do mundo publicamente e sem cessar e não pode jamais voltar a ser fechada, senão, apenas, para resguardar a nossa esperança num mundo mais verdadeiro, livre e humano!

PALAVRAS-CHAVE: parrhesia, libertas, ação comunitária ou sócio-política estoica, liberdade, direito de saber.

ABSTRACT: Greek parrhesia and its Roman equivalent, libertas, was the civic duty to tell the truth, the whole truth, before the powerful (rulers) to defend an important principle or right for the whole society, regardless of the real personal risks that those who exercising it could suffer, including death itself. In the period of classical antiquity, it was defended and practiced by Socrates and by the philosophical schools derived from his thought, especially cynicism and stoicism. Here we focus on parrhesia as a way of exercising stoic community or socio-political action, prioritizing the greater good of the whole, and we bring it to contemporary times, finding in the figure of Julian Assange the greatest living representative of parrhesia who, due to the very nature of concept, in realizing the common good for all by denouncing and showing the 
truth about the corrupt actions, war crimes and crimes against humanity of various governments and companies, became the target of powerful persecution, smear campaign and attempt, unfortunately successful, to make him an international pariah. Now, at the time of his judgment about his possible extradition to the United States, he has been suffering even more, in a Kafkaesque trial and being subjected to psychological and physical torture. However, even though he has suffered countless injustices for long ten years and may be extradited to the United States and suffer a new unfair trial, inhuman and cruel treatment, as well as being sentenced to a prison sentence of such an extent that it will become capital punishment, a life sentence, everything he gave us courageously in defense of freedom of expression, freedom of the press and the right to know what government officials do in our names without our authorization, will never be forgotten and will continue to be multiplied forever, like a Pandora's box that expels all the evils of the world publicly and without ceasing and can never be closed again, but only to safeguard our hope in a more real, free and human world!

KEYWORDS: parrhesia, libertas, stoic community or socio-political action, liberty, right to know.

$\mathrm{Na}$ antiguidade clássica, a parrhesia era um conceito muito importante para os gregos, especialmente para o filósofo Sócrates e para as escolas filosóficas derivadas de seus ensinamentos, principalmente o cinismo do final da era grega, no séc. I AEC, e o estoicismo do período da república e início do Império Romano, no séc. I EC.

A parrhesia grega e a libertas, seu equivalente romano, consistiam no dever cívico de falar a verdade perante os poderosos, os governantes, na defesa de um direito ou princípio importante para toda a sociedade, ainda que isso causasse risco real, inclusive à própria vida, daquele que a exercia. E, frequentemente, esse risco se concretizava, como foi o caso da condenação à morte por "suicídio"33 tanto de Sócrates quanto de Sêneca e da condenação ao exílio de Musônio Rufo e Epicteto. Seu conceito é assim descrito:

"Parrhesia, a estratégia retórica de falar a verdade ao poder que perturba o status quo e trabalha para realinhar a dinâmica do poder. A parrhesia é invocada quando os oradores atuam de maneiras que são potencialmente perigosas para sua própria segurança, mas o fazem a

\footnotetext{
${ }^{3}$ Usamos suicídio entre aspas pois, em nosso entendimento, o verdadeiro suicídio é voluntário, não podendo sem imposto por uma sanção externa. Sendo este último o caso, deve receber outro nome, o qual, no entanto, desconhecemos.
} 
serviço de valores de verdade profundamente arraigados que podem ser mais importantes de articular do que a própria vida ou segurança do orador ${ }^{4}$

Foi muito usada pelos filósofos estoicos, posto que era parte essencial da ação comunitária ou sócio-política em prol do bem comum e maior que clamavam ser dever de todo ser humano pelo fato de sermos parte de um todo muito maior, sermos verdadeiros cidadãos do Cosmos e, por isso, devermos ter sempre em mente que o todo é mais importante que a parte, e a cidade mais que o cidadão, guiando nossas ações por esse princípio comunitarista.

Esse dever cívico caiu no esquecimento após a queda do Império Romano. Porém, sempre houve pessoas de coragem que dedicaram suas vidas a cumpri-lo em prol do bem maior de sua comunidade e de toda a humanidade, tais como Mandela, Gandhi, Rosa Parks, Ruth Bader Ginsburg (recentemente falecida), dentre muitas outras.

Julian Assange é o maior arauto da parrhesia ou libertas vivo. Foi um jovem de inteligência acima da média e ideais humanitários, matemático e programador de computadores autodidata, especializado em criptografia e, sim, hacker, que sonhou construir um lugar online seguro para o qual qualquer pessoa pudesse enviar documentos sigilosos de governos e empresas que comprovassem a prática de corrupção e crimes em geral, para que esses fossem publicados na íntegra com o devido sigilo e proteção às fontes, por tratar-se de órgão jornalístico.

No que tange à exposição da verdade, de toda a verdade, sem cortes, não podemos deixar de comparar a ação de Assange com a dos estoicos Musônio Rufo e Epicteto por meio dos seguintes trechos:

"Todo lançamento de material que fazemos tem uma segunda
mensagem que é: "Nós mostramos exemplos". Se você se mostrar
imoral, com comportamento injusto, nós descobriremos e

\footnotetext{
${ }^{4}$ FREY, Renea C. Speaking truth to power: recovering a rhetorical theory of parrhesia. Electronic Thesis or Dissertation. Miami University, 2015. Disponível em: https://etd.ohiolink.edu/ . Acesso em 26 set. 2020.
} 
revelaremos. E você sofrerá as consequências". Julian Assange ${ }^{5}$

“O princípio do não se abster de fazer coisas vergonhosas é o não se abster de dizer coisas vergonhosas." Musônio Rufo ${ }^{6}$

"Quando discernires que deves fazer alguma coisa, faz. Jamais evites ser visto fazendo-a, mesmo que a maioria suponha algo diferente sobre $<$ a ação $>$. Pois se não fores agir corretamente, evita a própria ação. Mas se <fores agir> corretamente, por que temer os que te repreenderão incorretamente?" Epicteto ${ }^{7}$

Ou seja, o erro não está na publicação dos atos governamentais sigilosos, mas no mérito moral dos atos em si. Pessoas públicas têm o dever de dar total transparência aos seus atos. Se não o fazem, é porque têm algo a esconder, porque agiram de forma imoral, injusta ou ilegal, e isso necessariamente deve vir a público. E foi desse papel que Julian Assange se imbuiu, ou que o logos lhe deu na peça teatral que encenamos em nossas vidas, mas na qual não nos cabe escolher nosso papel, apenas bem desempenhálo, conforme nos diz Epicteto no capítulo XVII do Encheiridion.

De seu sonho nasceu o polêmico site Wikileaks, em 2006, um local revolucionário de liberdade jamais vista que deu à luz centenas de milhares de leaks (vazamentos), ajudando diretamente na derrubada de ditaduras africanas e do Oriente Médio, na chamada Primavera Árabe, bem como levando ao colapso todo o sistema bancário da Islândia, à época, eivado de nepotismo, corrupção e outros crimes. A

\footnotetext{
${ }^{5}$ WIKIREBELS. Documentário, Wikileaks. Disponível em: https://youtu.be/W3p62tAq84M . Acesso em 27 set. 2020

${ }^{6}$ DINUCCI, Aldo. Fragmentos menores de Caio Musônio Rufo. IN: Trans/form/ação, v. 35.3, fragmento 26 (Estobeu 3.6.22), p. 270, 2012. Disponível em https://www.scielo.br/scielo.php?script=sci_arttext\&pid=S0101-31732012000300015 . Acesso em 14 set. 2020.

${ }^{7}$ DINUCCI, Aldo; JULIEN, Alfredo. O Encheirídion de Epicteto, edição bilíngue. Parágrafo 35, p. 51. São Cristóvão: EdiUFS, 2012.
} 
filosofia do Wikileaks e de seu fundador Julian Assange é levar ao conhecimento de toda a humanidade crimes praticados às escuras pelos poderosos, seja por governos ou empresas, publicando toda a verdade, sem cortes ou edições, e protegendo as fontes. $\mathrm{Ou}$ seja, a perfeita prática da parrhesia, falar toda a verdade perante os poderosos, não importando as consequências que poderiam vir a sofrer por isso, levantando a bandeira da liberdade de expressão, da liberdade de imprensa e do direito fundamental de saber a verdade sobre o que os nossos governantes fazem em nossos nomes sem a nossa autorização, sendo estes Direitos Humanos inalienáveis.

A grande quantidade de furos jornalísticos dados pelo Wikileaks catapultou a figura de seu criador, Julian Assange, como jornalista investigativo de fama global e mudou para sempre o papel da imprensa e o modo de fazer jornalismo. Os documentos "classificados" ou "secretos" chegavam em grande quantidade e velocidade, sendo verificada a sua veracidade pela equipe e protegidas as fontes e, rapidamente, eram publicados os segredos mais obscuros de vários governos para o mundo inteiro ver, com acesso livre e integral aos documentos originais, bastando, para acessá-los, uma simples conexão com a internet.

Em 2010, a maior de todas as suas "bombas jornalísticas" foi publicada: vídeos mostrando um ataque aéreo feito pelos militares americanos no Iraque, matando, deliberadamente - como quem joga videogame, aos risos dos militares que atiravam -, civis, homens, crianças e, inclusive, dois jornalistas que lá estavam cobrindo a guerra, vídeos estes denominados de Collateral Murder (assassinato colateral). Junto com esses vídeos, o Wikileaks também publicou mais de 250 mil documentos e telegramas diplomáticos sigilosos do governo dos EUA com registros das guerras do Afeganistão e do Iraque, reportando a morte de milhares de civis, bem como um manual de instruções para o tratamento cruel a ser dado aos prisioneiros políticos da prisão militar americana de Guantanamo Bay, em $\mathrm{Cuba}^{8}$, no que ficou conhecido como caso Cablegate, o maior vazamento público de documentos governamentais sigilosos da história ${ }^{9}$.

Tais vazamentos tiveram uma enorme repercussão internacional, por levar à luz

\footnotetext{
${ }^{8}$ WIKILEAKS. In: Wikipedia. Disponível em: https://pt.m. wikipedia.org/wiki/WikiLeaks . Acesso em 25 set. 2020.

${ }^{9}$ UNITED STATES DIPLOMATIC CABLES LEAK. In: Wikipedia. Disponível em: https://en.wikipedia.org/wiki/United_States_diplomatic_cables_leak. Acesso em: 30 set. 2020.
} 
do conhecimento público tamanhas e tantas atrocidades governamentais, cometidas em nome do povo americano. O que muitos não sabiam é que o Wikileaks foi indicado ao Prêmio Nobel da Paz por 6 anos consecutivos, de 2010 a 2015, dentre inúmeros outros prêmios recebidos pela organização e seu fundador pela criação de uma nova mídia, pelo seu jornalismo investigativo e, principalmente, pela defesa dos Direitos Humanos, por ser ele "uma das contribuições mais importantes para a liberdade de expressão e transparência no século XXI." 10

Todavia, paradoxal e ironicamente, aqueles que lutam pela verdade e pela liberdade para toda a humanidade, quando conseguem realizá-las, perdem a própria liberdade e seus Direitos Humanos mais fundamentais, pois o mundo não é capaz de lidar com a verdade, preferindo permanecer na caverna platônica eternamente, protegido pelo comodismo do status quo, e os poderosos querem, por óbvio, manter o seu poder a todo custo e, por isso, perseguem violentamente qualquer um que revele a verdade inconveniente ${ }^{11}$ de seus atos corruptos ou criminosos.

E é exatamente essa fúria que Assange vem sofrendo desde 2010, há 10 longos anos. Se antes já tinha pouca liberdade pela revelação dos segredos de vários outros governos e empresas, dali em diante, jamais teve qualquer liberdade ou dignidade humana, pois passou a sofrer grande perseguição e poderosa campanha de difamação internacional pelo governo dos EUA e seus aliados políticos.

Residente da Suécia, país onde tinha sede o Wikileaks, escolhido por sua legislação amplamente protetiva das liberdades de expressão e de imprensa, viu a campanha difamatória americana transformar-se num processo de assédio sexual e estupro contra ele baseado em fatos que lá teriam ocorrido e, portanto, sob a jurisdição sueca, tendo esta emitido à Interpol ${ }^{12}$ um mandado de prisão internacional, válido em 188 países, no final de 2010 .

Tratava-se de acusação falsa derivada de um acordo obscuro entre o governo

\footnotetext{
${ }^{10}$ Conforme o parlamentar norueguês Snorre Valen, responsável pela indicação do Wikileaks ao Prêmio Nobel da Paz em 2011. Fonte: WIKILEAKS. In: Wikipedia. Disponível em: https://pt.m.wikipedia.org/wiki/WikiLeaks . Acesso em 25 set. 2020.

${ }^{11}$ UMA VERDADE INCONVENIENTE (AN INCONVENIENT TRUTH). Documentário: Al Gore, 2006. Disponível em: https://web.archive.org/web/20130731023115/http://vimeo.com/24857305 . Acesso em 30 set. 2020.

${ }^{12} \mathrm{~A}$ Interpol é uma força policial internacional.
} 
sueco e o americano. Além de difamá-lo ainda mais, este processo infundado permaneceu em juízo por anos, sendo arquivado por falta de provas apenas em $2019^{13}$, com o grande risco subjacente de, sendo ele preso pelo governo sueco, ser extraditado para os Estados Unidos para ser julgado pelo "crime" de revelar a verdade sobre os atos cruéis e desumanos praticados pelo governo de tal país.

Dessa forma, foi tornado um pária internacional e considerado hacker, cyberterrorista e abusador sexual pelos incautos que acreditaram na fortíssima campanha difamatória americana contra ele. Sua imagem pública foi manchada em definitivo, o que levou ao esquecimento de seu caso pela falta de cobertura da imprensa.

Fugiu para Londres e chegou a se entregar à polícia do Reino Unido em dezembro de 2010, sendo libertado após 10 dias de detenção com o pagamento de fiança. Todavia, seu processo de extradição para os EUA continuou, e não lhe restou alternativa senão buscar refúgio político, que obteve em agosto de 2012, passando a residir na Embaixada do Equador em Londres onde, por se tratar de território equatoriano, estava protegido da polícia e da jurisdição inglesa. Seu refúgio se tornou sua prisão, pois dele não podia sair sob nenhuma circunstância, sob pena de ser imediatamente preso e extraditado para os Estados Unidos.

Lá permaneceu até abril do ano passado, 2019, quando o Equador retirou, ilegalmente, o direito de asilo político de Assange e, em ação orquestrada com o governo britânico, permitiu que ele fosse preso dentro da própria Embaixada, um absurdo jurídico jamais visto. A partir de então, e até hoje, está preso em cela solitária na prisão inglesa de segurança máxima de Belmarsh.

No mesmo dia, "coincidentemente", o Departamento de Justiça americano formalizou denúncia contra Assange sob a acusação de conspiração para hackear a rede do Departamento de Defesa para obter os documentos que, posteriormente, foram publicados pelo Wikileaks e levaram a conhecimento público os inúmeros crimes de guerra e crimes contra a humanidade cometidos pelo governo dos EUA por meio de suas forças militares.

\footnotetext{
${ }^{13}$ JULIAN ASSANGE. In: Wikipedia. Disponível em: https://pt.m.wikipedia.org/wiki/Julian_Assange . Acesso em 25 set. 2020.
} 
Mais adiante, sua denúncia foi completamente alterada no decorrer do processo, ato ilegal perante qualquer ordenamento jurídico, posto que a acusação deve sempre preceder a defesa, jamais o contrário, vez que, sabedora dos elementos integrais de sua defesa, a acusação posterior fere seus Direito Humanos fundamentais ao devido processo legal e à ampla defesa.

Atualmente, desde o dia 07 de setembro, o processo de extradição de Julian Assange para os EUA está sendo julgado num tribunal de Londres, em um julgamento secreto e kafkiano $^{14}$, cuja sentença deve ser prolatada e publicada em janeiro de 2021.

Este processo, juridicamente, está recheado de ilegalidades frente ao Direito Internacional Público, aos Direitos Humanos e ao Direito Constitucional e infraconstitucional norte-americano e inglês.

Tais ilegalidades foram muito bem elencadas em uma grande carta escrita pela organização Lawyers for Assange (advogados por Assange), e esta foi subscrita por mais de 160 autoridades internacionais, como presidentes, primeiros-ministros, diplomatas, entre outros ${ }^{15}$, sendo dirigida ao primeiro-ministro inglês e demais autoridades responsáveis pelo caso, requerendo a retirada de todas as acusações e do processo de extradição contra Assange.

Listamos aqui, apenas, as mais graves e evidentes delas, in verbis:

- Julgamento perante o "Tribunal de Espionagem da Virgínia", com base no "Espionage Act", legislação esta somente aplicável a servidores militares e agentes americanos da CIA, FBI e NSA. Não é possível aplicá-la a qualquer pessoa fora dessas hipóteses, muito menos a um estrangeiro - Assange é australiano -, menos ainda tendo sido cometidos tais "crimes" em território estrangeiro - o Wikileaks era sediado na Suécia quando do vazamento de 2010, objeto das acusações contra

\footnotetext{
${ }^{14}$ Referência ao livro "O processo" de Franz Kafka, em que o personagem principal é processado sem saber porquê, sem direito à defesa ou, sequer, a um advogado (a) e acaba por ser condenado desta forma absurda e antijuridica.

${ }^{15}$ Leia a carta na íntegra no site https://www.lawyersforassange.org/pt/open-letter.html .
} 
Assange - e, jamais, contra um jornalista no estrito cumprimento do seu dever profissional - recebera os documentos, protegera suas fontes e os publicara, nada mais.

- Tratar-se-á de julgamento secreto nos EUA, com júri formado por integrantes do Departamento de Defesa, da CIA, FBI, NSA e/ou Departamento de Segurança Interna, o que fere de morte o devido processo legal, que é um conjunto de princípios do Direito Internacional Público e dos Direitos Humanos $^{16}$.

- Violação da privacidade do réu, do sigilo clienteadvogado e, com isso, negação ao seu direito à ampla defesa ${ }^{17}$, pelo fato de todas as suas comunicações dentro da Embaixada do Equador em Londres terem sido secretamente gravadas em áudio e vídeo, supostamente pela CIA, bem como por todos os seus pertences, inclusive e principalmente, documentos legais, anotações, computadores, notebooks, celulares, pendrives e afins terem sido apreendidos, certamente invadidos e jamais devolvidos pela polícia inglesa quando de sua prisão.

- $\quad$ Alteração da denúncia feita pelos EUA em Maio de 2019 em meio ao processo e sem aviso prévio, impossibilitando, novamente, a ampla defesa do réu e seu direito ao devido processo legal. De 1 (uma) acusação de conspiração advieram 18 (dezoito) novas acusações contra Assange, todas especificamente relacionadas aos vazamentos de 2010, sendo ele acusado de divulgar segredos de Estado e, assim, prejudicar a segurança nacional americana, crimes puramente políticos, com o consequente aumento da pena prevista para o caso de condenação para, pelo menos, 175 anos de prisão em regime fechado, ou seja, prisão perpétua, pena capital.

\footnotetext{
${ }^{16}$ Artigo 14 do "International Covenant on Civil and Political Rights" da ONU. Disponível em: https://www.ohchr.org/en/professionalinterest/pages/ccpr.aspx . Acesso em 26 set. 2020.

${ }^{17}$ Idem supra e artigo 80 da Convenção Européia de Direitos Humanos (CEDH).
} 
- Violação da impossibilidade de extradição de qualquer pessoa por crimes políticos, de acordo com o Direito Internacional dos Tratados e o artigo 4o do Tratado de extradição entre o Reino Unido e os Estados Unidos, especificamente.

- $\quad$ Risco real de ser submetido à tortura e a tratamento cruel ou desumano em caso de extradicao para os EUA, comprovado pelo relator da ONU sobre tortura e já admitido pelo próprio governo americano, o que contraria o princípio de não-repulsão consagrado em todo o Direito Internacional Público e, especialmente, no Direito dos Refugiados.

- Violação direta da liberdade de imprensa, da liberdade de expressão e do direito do povo de saber a verdade sobre os atos praticados por seu governo em seu nome, Direitos Humanos fundamentais e integrantes da 1a Emenda da Constituição dos Estados Unidos da América.

- $\quad$ "O Relator das Nações Unidas sobre Tortura concluiu que "O Sr. Assange foi deliberadamente exposto, durante um período de vários anos, a formas persistentes e progressivamente graves de tratamento ou punição cruel, desumano ou degradante, cujos efeitos cumulativos só podem ser descritos como tortura psicológica" $^{18}$.

- Violação de seus Direitos Humanos à saúde e à vida, restando sua saúde física fragilizada, com doença pulmonar não tratada, e seu estado psíquico extremamente abalado pela perseguição, tortura psicológica e isolamento por cerca de uma década, sendo ele portador de Síndrome de Asperger, um tipo de autismo altamente funcional que, no entanto, aumenta consideravelmente o seu risco de suicídio, já estando

\footnotetext{
${ }^{18}$ Vide item "C" da carta aberta da Organização Lawyers for Assange. Disponível em: https://www.lawyersforassange.org/pt/open-letter.html . Acesso em: 25 set. 2020.
} 
comprovado seu estado depressivo, o que também segue sem tratamento por impedimento das autoridades equatorianas, anteriormente, e inglesas, desde sua prisão ${ }^{19}$.

- Negação do direito do réu de se comunicar com seus advogados desde março do corrente ano, inclusive durante o julgamento, em que vem sendo mantido trancado numa cabine de vidro à prova de balas que fica atrás da tribuna em que estão seus advogados, tendo estes que ficar de costas para ele, não podendo se comunicar com ele, sequer, por sinais.

- Julgamento "secreto", com impossibilidade de acompanhamento pelo público e, principalmente, pela imprensa, que só pode entrar em número restrito e não pode gravar as audiências por nenhum meio.

Comprova-se, destarte, que exercer a parrhesia é realmente perigoso e que expor a verdade custa caro. Entretanto, pelo próprio princípio, isto é parte inerente deste dever cívico que temos perante toda a humanidade e o Cosmos.

Esperamos que, neste caso, a justiça seja feita e que Julian Assange não tenha que pagar com a própria vida por ter nos dado o direito de saber dos horrores que os governos cometem em nossos nomes sem que saibamos ou tenhamos dado autorização para isso.

Entretanto, se o pior acontecer, seu exemplo jamais perecerá e seu trabalho continuará por meio do próprio Wikileaks e dos feitos de inúmeros seguidores que multiplicam a divulgação da verdade por todos os cantos do mundo digital e material.

Cabe a nós dar visibilidade ao caso de Assange, já que a imprensa internacional não está dando a cobertura devida a ele, e propagarmos a defesa dos Direitos Humanos da liberdade de imprensa e expressão e do direito de saber a verdade sobre os atos de nossos governantes.

\footnotetext{
${ }^{19}$ Conforme testemunhos médicos de um neuropsiquiatra e um psiquiatra que o avaliaram como peritos de sua defesa e, também, surpreendentemente, corroborados pelo especialista em suicídios em prisões chamado pela acusação. Fonte: https://www.assangedefense.org . Acesso em 20 set. 2020.
} 
Como nos disse o próprio Julian Assange: "O público tem o direito de conhecer os materiais e os registros históricos. Tem o direito de ter materiais de importância diplomática, política, étnica ou histórica. Se alguma coisa está interferindo nesse processo, vamos desfazê-la" ${ }^{20}$.

Se o tornam um Prometeu acorrentado e perpetuamente torturado e calado, jamais conseguirão roubar-nos o fogo divino que ele nos deu. O legado de Assange e do Wikileaks é um ponto sem retorno, e a caixa de Pandora que foi por ele aberta continuará a expelir todos os males do mundo publicamente, jamais podendo voltar a ser fechada, senão, apenas, para resguardar nossa esperança num mundo mais verdadeiro, livre e humano!

\section{REFERÊNCIAS}

ASSANGE DEFENSE ORGANIZATION. Disponível em: https://www.assangedefense.org . Acesso em 20 set. 2020.

DINUCCI, Aldo. Fragmentos menores de Caio Musônio Rufo. IN: Trans/form/ação, v. 35.3, fragmento 26 (Estobeu 3.6.22), p. 270, 2012. Disponível em https://www.scielo.br/scielo.php?script=sci_arttext\&pid=S0101-31732012000300015 . Acesso em 14 set. 2020.

DINUCCI, Aldo; JULIEN, Alfredo. O Encheirídion de Epicteto, edição bilíngue. Parágrafo 35, p. 51. São Cristóvão: EdiUFS, 2012.

EUROPEAN CONVENTION ON HUMAN RIGHTS (ECHR) - CONVENÇÃO EUROPÉIA DE DIREITOS HUMANOS (CEDH). 1950. Artigo 80. Disponível em: https://echr.coe.int/Pages/home.aspx?p=basictexts\&c= . Acesso em 28 set. 2020.

FREY, Renea C. Speaking truth to power: recovering a rhetorical theory of parrhesia. Electronic Thesis or Dissertation. Miami University, 2015. Disponível em:

\footnotetext{
${ }^{20}$ WIKIREBELS. Documentário, Wikileaks. Disponível em: https://youtu.be/W3p62tAq84M . Acesso em 27 set. 2020
} 
https://etd.ohiolink.edu/ . Acesso em 26 set. 2020.

INTERNATIONAL COVENANT ON CIVIL AND POLITICAL RIGHTS. Organização das Nações Unidas (ONU). Artigo 14. Disponível em: https://www.ohchr.org/en/professionalinterest/pages/ccpr.aspx . Acesso em 26 set. 2020.

JULIAN ASSANGE. In: Wikipedia. Disponível em: https://pt.m.wikipedia.org/wiki/Julian_Assange . Acesso em 25 set. 2020.

KAFKA, Franz. O processo. Tradução de Marcelo Backes. Porto Alegre: L\&PM, 2013. LAWYERS FOR ASSANGE. Carta Aberta ao Primeiro Ministro do Reino Unido, Boris Johnson, à Ministra do Interior, Priti Patel, ao Lord Chancellor e Ministro da Justiça, Robert Buckland Q . Disponível https://www.lawyersforassange.org/pt/open-letter.html . Acesso em 26 set. 2020.

LEIGH, David; HARDING, Luke. WikiLeaks: a guerra de Julian Assange contra os Segredos de Estado. Campinas (SP): Verus, 2011, Edição Kindle, posição 380.

O QUINTO PODER (THE FIFTH ESTATE). Diretor Bill Condon. Estados Unidos: Dreamworks, 2013. Disponível em: https://youtu.be/iZtrX03P_0s . Acesso em 26 set. 2020 .

UMA VERDADE INCONVENIENTE (AN INCONVENIENT TRUTH). Documentário: $\quad \mathrm{Al}$ Gore, 2006. Disponível em: https://web.archive.org/web/20130731023115/http://vimeo.com/24857305 . Acesso em 30 set. 2020 .

UNITED STATES DIPLOMATIC CABLES LEAK. In: Wikipedia. Disponível em: https://en.wikipedia.org/wiki/United_States_diplomatic_cables_leak . Acesso em: 30 set. 2020.

WIKILEAKS. In: Wikipedia. Disponível em: https://pt.m.wikipedia.org/wiki/WikiLeaks . Acesso em 25 set. 2020.

WIKIREBELS. Documentário, Wikileaks. Disponível em: https://youtu.be/W3p62tAq84M . Acesso em 27 set. 2020 
PROMETHEUS - N. 35 - January-April 2021 - E-ISSN: 2176-5960 